\title{
Method for Producing Bakery Products Using Phospholipid Concentrate of Safflower oil
}

\author{
S. Altayuly ${ }^{1}$, G.O. Magomedov ${ }^{2}$, E.I. Ponomareva ${ }^{2}$, \\ A.I. Iztaev $^{3}$, G.K. Iskakova ${ }^{3}$ and G.B. Baimagambetova ${ }^{3}$ \\ ${ }^{1}$ Eurasian national university named by L.Gumileva. Kazakhstan, 010000, \\ Astana, Munaytpasova 5, \\ ${ }^{2}$ Voronezh State University of Engineering Technology.Russian Federation, \\ 394036, Voronezh, Sakko and Vanceti 72 \\ ${ }^{3}$ Almaty Technological University, Kazakhstan, 020000, Almaty, Tole bi 100. \\ DOI: http://dx.doi.org/10.13005/bbra/1906 \\ (Received: 20 September 2015; accepted: 21 November 2015)

\begin{abstract}
The article is devoted to the topic today, a healthy diet, to be more precise, it describes a method of removing moisture from the phospholipids emulsion safflower oils, and subsequent usage of phospholipids concentrate in the production of dietary bakery products whole grain and malted milk. (Magomedov,2006;)
\end{abstract}

Key words: bakery, concentrate, safflower oil, development, whole grain, dietary.

The purpose of development of a production way of bakery products, receiving a new product, improvement of quality of bread, decrease in losses of solids, increase of an exit, expansion of the range of the whipped bakery products, decrease in energy consumption and product cost, and also increase of a nutrition value of products that conforms to modern requirements about a balanced diet and healthy food is. (Magomedov,2005;)

Adding to the daily diet of bread from whole grain wheat with the adding of food phospholipids concentrate in food can reduce the formation of free radicals in the body and reduce the risk of cardiovascular diseases, cancer, atherosclerosis, diabetes, prevents premature aging of the human body (Altayuly, 2012;). Development of a new method of production of

\footnotetext{
* To whom all correspondence should be addressed.
}

bakery products, which provides a relevant science to modern requirements of a balanced and healthy diet dietary competitive bakery. (Altayuly, 2011;). Method

This method allows to improve the quality of the finished product, increase the output of bread, to intensify the process of making the product, get bread for the dietary use, increase vitamin and mineral composition, slow the staling of the finished product, reduce the labor intensity and energy intensity of the manufacturing process (Altayuly, \& Alikulov, 2012;).

To extract from safflower oil of phospholipids and other hydrophilic substances are in the process of hydration, which is formed as a result of a thermodynamically unstable system, coagulate phospholipids, the system is divided into two phases (oil and phospholipid emulsion). (Altayuly, 2010;). After centrifugation, the separators prepared in hydrated phospholipid and oil emulsion, the latter has a different composition: $55-70 \%$ water (by total weight), $15-30 \%$ phospholipids, and $15-20 \%$ oil. To increase the shelf 
life and improve quality of food phosphate concentrates phospholipid emulsion is dewatered in a thin layer at a temperature of $60-75 \mathrm{C}^{\circ}$, the residual pressure of $2.66 \mathrm{kPa}$ to a moisture content in it is less than $1 \%$. Remove moisture from the phospholipid emulsion of safflower oils produced at the new design rotary foil devices of continuous action (Ziggers,1993).

The biotechnological method of producing bakery products is carried out as follows:

Malted milk obtained for oats grains of washed and incubated in the drinking water at a temperature of $20^{\circ} \mathrm{C}$ for 30 hours, then washed and subjected to germination for 50 hours to germs size of $1.5 \mathrm{~mm}$. Sprouted grain oat is shredded by passing through a cutter with the hole diameter 2 $\mathrm{mm}$, the liquor prepared $1: 3$, then the fermentation is carried out for 26 hours. (Altayuly et al, 2001;). A ephospholipid food concentrates by hydration of crude sunflower oil. Semi-finished product is prepared in two steps from the whole grain, malted milk, food phospholipid concentrate, salt cooked in a food and drinking water.(Smit, 1999;)

Whipped unleavened semi-finished products produced by mechanically breaking up under the pressure in the experimental laboratory facility, developed at the Department THMKP (Fig. $1)$. It consists of the following components: 1 whipping camera; 2 - asynchronous motor (type AIR 80V6U2 GOST 163-74); 3 - remote control; 4 - compressor (MEGAFER HP 1.5); 5 - the thermostat; 6 - unloading opening.(Lunning,2002;)

The installation operates as follows. Prescription dough ingredients are fed through feed inlet kneading body in a batch kneading machine in which the mixing tool is set in a corolla driven by a variable speed motor.(Leaper, 1997;)

Upon termination of loading the kneading case of the dough mixing car is hermetically closed by a cover and dough within 3-5 min. in a frequency of rotation of kneading body is kneaded $5 \mathrm{~s}-1$. Then atmospheric air under pressure of 0,3-0,4 MPas is entered into the camera via the union under excessive pressure in the kneading case, and the semi-finished product continues to get off 3-10 min. with a frequency of rotation of kneading body 9,2 with-1 and at the same time to be loosened.(Jongen,1999;)

During the dough kneading continuous supply of temperature-controlled water $\left(20-25^{\circ} \mathrm{C}\right)$ in a shirt kneading machine is made. Thus there is a churning prescription components and saturation test air mass are produce.(Altayuly et al,2012;)

The dough prepared in this way is foam mass with stable physical and chemical characteristics. Upon completion of the churning process the dough pieces formed under a pressure of 0.4 MPa through discharge opening kneading machine.(Green,1993;)

After completion of knocking down process the test preparations in weighing $0,25 \mathrm{~kg}$

Table 1. The organoleptic and physico-chemical quality of the dough and bread

The name of indicators

Organoleptic

Appearance: Form

Surface

Color

condition of the crumb

Taste and smell

Physico-chemical

The density of test, $\mathrm{g} / \mathrm{cm}^{3}$ Specific volume, $\mathrm{cm}^{3} / 100 \mathrm{~g}$ The output of bread, $\%$ The shelf life of products, $h$
Values of the quality of bread prepared according to Example Control

Examole
Correct corresponding grain form

which made pastries, with several convex upper crust.

Smooth, without cracks and explosions

Golden Brown

Elastic

Peculiar to bread from flourwhole grain of wheat, without foreign smack and a smell

$\begin{array}{ll}0,46 & 0,40 \\ 195 & 240 \\ 136 & 148 \\ 96 & 120\end{array}$

Peculiar to akhloridny bread from flour of whole grain of wheat, with sweetish smack

0,40

240

120 
with a working pressure are form, the formed test preparations bake at a temperature of $250 \pm 2{ }^{\circ} \mathrm{C}$, within $35 \mathrm{~min}$. (Magomedov et al, 2010;)

The scheme is a production line of kneading bread with usage of the phospholipids of emulsions of sunflower oils is submitted in figure 2.

Semi-finished product is prepared in the following ratio, g:

Whole-grain wheat flour

Food phospholipid concentrate Malted milk
Table salt $\quad 1.3$

Water

Water is taken in view of moisture in raw materials, so that the humidity test was 54\%.(Ryazanov,2009;)

\section{RESULTS}

Ready bakery products were analyzed on 80 organoleptic and physico-chemical parameters 3 (Ponomarev, 2008;). Analytical data presented in 20 Table 1.

Table 2 . Performance components of bakery products

\begin{tabular}{lllll}
\hline $\begin{array}{l}\text { S. } \\
\text { No }\end{array}$ & $\begin{array}{l}\text { Name of the } \\
\text { component }\end{array}$ & $\begin{array}{l}\text { Daily } \\
\text { maintenance }\end{array}$ & $\begin{array}{l}\text { Contents in } 100 \mathrm{~g} \\
\text { of product, g }\end{array}$ & $\begin{array}{l}\text { The degree } \\
\text { of satisfaction, } \%\end{array}$ \\
\hline 1 & Proteins, g & 75 & 12,98 & 17,32 \\
2 & Fat, g & 83 & 10,71 & 12,92 \\
3 & Carbohydrates, g & 365 & 39,97 & 10,95 \\
4 & Dietary Fiber, g & 30 & 6,87 & 22,9 \\
5 & Mineral substances,mg: & & & \\
6 & Ca & 1000 & 42,32 & 4,23 \\
7 & Na & 2400 & 51,36 & 2,14 \\
8 & K & 3500 & 374,2 & 10,69 \\
9 & P & 1000 & 252,0 & 25,21 \\
10 & Mg & 400 & 64,85 & 16,22 \\
11 & Fe & 14 & 3,85 & 27,51 \\
12 & Vitamins, mg: & & & 26 \\
13 & B1 & 1,5 & 0,39 & 18 \\
14 & B2 & 1,8 & 0,18 & 22,2 \\
15 & PP & 20 & 4,83 & $228(54,45)$ \\
16 & Energy value of 100 g of product, kcal (kJ) & & \\
\hline
\end{tabular}

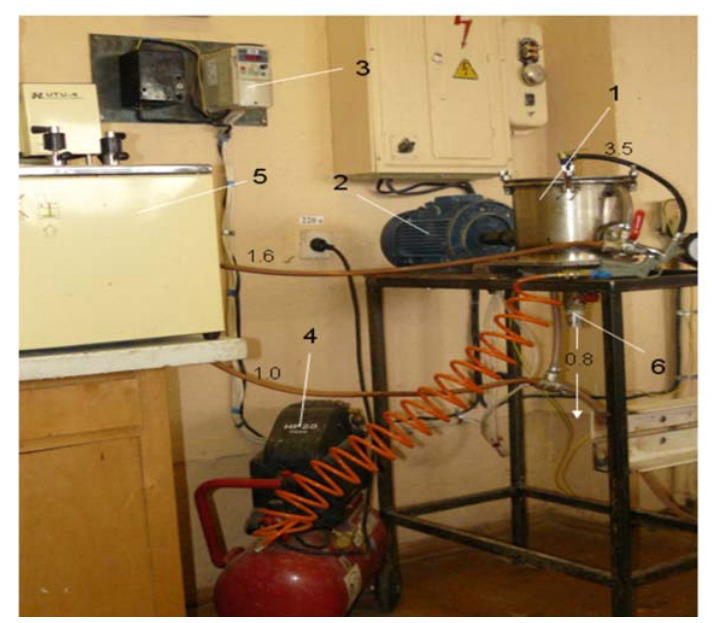

Fig. 1. Scheme of experimental laboratory installation

\section{DISCUSSION}

As seen from Table 1, whipped bread prepared from whole grain wheat flour using a food phospholipid concentrate, malted milk, table salt and potable water at the selected ratio of components i: whole grain wheat flour - 80 , food phospholipid concentrate - $2-4$, malted milk - 20, salt -1.3 , for the calculation of water, while stirring the phospholipid concentrate food, malted milk, table salt and water in the chamber at whipping speed of mixing body 3,34-6,67s -1 for 1-3 minutes, subsequently introducing whole grain wheat flour, and mixing for 8-12 minutes at the same mixing parameters, knocking down the dough under air pressure $0.35-0.45 \mathrm{MPa}$ for 6-10 min speed of mixing 


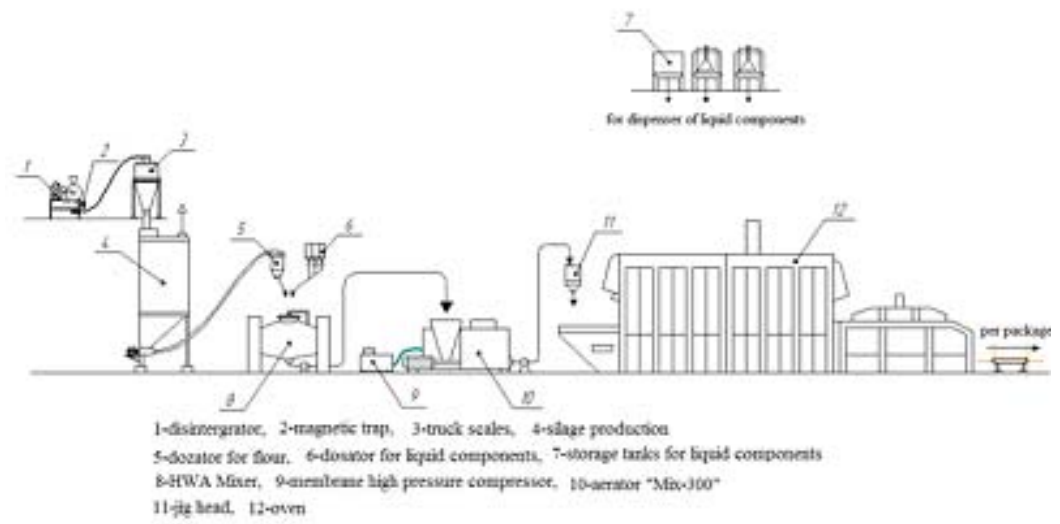

Fig. 2. Production line of whipped bread with phospholipid emulsions of sunflower oil

body 5-8,34s-1, forming and baking, has a high quality.(Magomedov,2009).

An exception to the formulation of compressed yeast is the usage of whole grain, edible phospholipid concentrate and malted milk from grain oat bread allow obtaining a functional purpose, to enrich bakery whipped filling with dietary fiber, vitamins, minerals, polyunsaturated fatty acids (Table 2).(Magomedov,2008;)

At a dosage of a food phospholipid concentrate less than $2 \mathrm{~g}$ on $80 \mathrm{~g}$ of flour, hashing of liquid components less than $1 \mathrm{~min}$. and a further batch of dough less than 8 min., its knocking down less than $6 \mathrm{~min}$. with a frequency of rotation less than $5 \mathrm{~s}-1$ aren't reached uniform distribution of prescription components on all weight, and the received semi-finished product doesn't possess the optimum properties necessary for receiving products of the best quality.(Magomedov,2008;)

At a dosage of a food phospholipid concentrate more than $4 \mathrm{~g}$ on $80 \mathrm{~g}$ of flour, hashing of liquid components more than 3 min. and further hashing of dough more than 12 min., its knocking down more than $8 \mathrm{~min}$. with a frequency of rotation more than 8,34-1 about stability of the received foam decrease and occur destruction of foamy structure of dough, air bubbles burst, quality of whipped bread worsens, the crumb of the baked bread is getting dark. (Magomedov,2007;)

The research in this area is dictated on the one hand, the necessity to meet the needs of ruminants essential polyunsaturated fatty acids (linoleic, linolenic), and on the other hand, improvement of livestock production dietetic qualities. It is known that as a result biogidrogenizatsii triglycerides in the rumen of ruminant adult adipose tissue contain high levels of saturated fatty acids, as well as the presence of products of incomplete hydrogenation.

Currently, various methods are described for the preparation of cattle and sheep feed additive containing vegetable fats. Basically they consist in the fact that the polyunsaturated vegetable fat enclosed in a protein coat, followed by treatment with formaldehyde. Protein shell treated with formaldehyde, is stable in neutral medium scar $(\mathrm{pH}$ 6-7). After hydrolysis at a more acidic environment of lower gastrointestinal tract polyunsaturated fat is digested and absorbed, resulting in the meat and milk of animals containing a large amount of polyunsaturated fats.

When feeding cows for seven days in $2278 \mathrm{~g}$ of spray-dried and treated with formaldehyde and sodium caseinate emulsion safflower oil, linoleic acid concentration in the milk fat increased until 30-35\% palmitic decreased from 35 to $14 \%$, myristic - 13 to $14 \%$. Prolonged feeding of supplements did not have a toxic effect on animals.

Incubation protected protein shell of safflower oil with reduced content of rumen hydrogenation of unsaturated fatty acids. Feeding this additive oxen improved digestibility of energy, dry matter and lipids. At the end of the experiment the level of lipids in the blood serum of animals treated with a protected safflower oil was $930 \mathrm{mg} \%$ was 2-fold higher than that of the oxen, fed a mixture of $6 \%$ of casein treated with formaldehyde and $6 \%$ 
of the untreated safflower oil. We oxen to give the protected safflower oil, oleic acid level in the blood serum decreased, and linoleic acid - increases. A similar pattern was observed in the fatty acid composition of phospholipids, glycerides, free fatty acids and cholesterol esters.

Processing feed formaldehyde is the most promising method of protecting proteins, amino acids and fat from destruction, it contributes to a more complete recovery and in the body of ruminants. This method provides a noticeable hair growth, has little effect on the increase in muscle mass and lactation, and also protects the fats from biogidrogenizatsii rumen and promotes the formation in tissues and milk fat, containing up to $35 \%$ of unsaturated fatty acids. In some cases, hut concentrates treated with formaldehyde significantly improves the fat and protein content in milk, which improves its taste. However, oil from such milk gets off badly.

In experiments on cows treated with formaldehyde to study the effect of high-calorie additives include up to $45 \%$ fat on milk yield, milk protein content and fat content and fatty acid composition. Feeding $1.25 \mathrm{~kg}$ (head 1) fat additive consisting of $25 \%$ tallow and $75 \%$ soybean $(45 \%$ fat), increased fat content in the daily milk yield, but did not alter the protein. Additive fat diet protected cows caused some reduction in milk acids with carbon chain lengths from C4 to C14, but significantly increases the concentration of C16-C18 saturated acids. About 24\% of the added fat passed into milk fat is in the form of high molecular weight acids.

When feeding cows sunflower seeds treated with formaldehyde, observed an increase in milk yield, milk fat, cholesterol and animal protein to decrease with increasing doses of milk feed (0 to $3.1 \mathrm{~kg}$ per head per day 1 ). Altered technological properties of milk fat in the milk increased 3-5 times the concentration of linoleic acid and the ratio of fatty acids C12 to $6 \%$ decrease, and reduced heat resistance of milk, rennet was weak clot and milk fat was less resistant to oxidation.

The effect of fat encapsulation of soy proteins and casein treated with formaldehyde, the degree of hydrogenation of unsaturated fatty acids in the rumen of cows. In this processing, soybean oil hydrogenation of linoleic acid in the rumen was reduced from 90 to $64 \%$. Digestibility of individual fatty acids ranged from 70 to $80 \%$, and linoleic acid was $90 \%$. Processing food formalin had no negative effect on fat digestibility. At low levels of linoleic acid in the diet (60 g) 40\% ee intestine pass into milk. Protection of fat hydrogenated enables ruminant feed it in large quantities without disturbing the rumen fermentation processes.

Significantly affected by the use of fat supplements are protected from biogidrogenization in the rumen, and lipid metabolism in sheep.

\section{CONCLUSION}

The offered way of production of bakery products with adding of a food phospholipid concentrate allows:

a) to increase quality of a finished product,

b) to increase a bread exit,

c) to intensify process of preparation of a product,

d) to receive bread of dietary appointment,

e) to raise vitamin and mineral structure,

f) to slow down process of a staling of a finished product,

g) to reduce laboriousness and power consumption of production process.

\section{REFERENCES}

1. Altayuly S. Scientific support the process of dripping from phospholipid emulsions of sunflower oil in the rotary-film devices [Text] / S. Altayuly // Abstract of dissertation for the degree of Doctor of Technical Sciences, Voronezh: VPO “VGUIT”, 2012; 50 p.

2. Altayuly S. Effect of phospholipids on the nitrite reducing activity of xanthine oxidase in milk [Text] / S. Altayuly, Z.Alikulov // Proceedings of the Moscow International Congress "Biotechnology: Section 5," Application of nanobiotechnology in medicine "(Moscow, 2022 March , 2012), - M .: ZAO “Expo-biochimtechnologies” MUCTR. DI Mendeleev, S.-2012568 S.217-219.

3. Altaiuly S. Effect of Phospholipids Restores the Activity of Xanthine Oxidase Nitrite in Milk [Òekst] / S. Altaiuly, A. Aimurziyeva, Z. Alikulov // International Scientific Conference on Regenerative Medicine \& Healthy Aging NAZARBAYEV UNIVERSITY Center for Life Sciences November 2012 Astana, Republic of Kazakhstan. Pp.47-48. http://www.conference- 
rmha.com

4. Magomedov G.O., Altayuly S. Ponamareva E.I., I.A Aleynik. A method of producing bakery products [Text] / The patent for the invention. 12464788 RF IPC A 21 D 13/02. Applicant and patentee Voronezh. state. tehnol. Acad. - 1 2010135850/13; appl. 26.08.2010; publ. appl. 20.03.2012. Bull. ${ }^{1}$ 8. Publ. 27.10.2012. Bull. 130-7s.

5. Altayuly S. Dzherembaeva NE, Beloslyudtseva AA .; The preliminary patent RK ${ }^{1}$ 9785, IPC A21D 2/36. A method of producing buns bakery products, applicant and patentee Rep. state. State Enterprise "Kazakh Research Institute of Horticulture and Viticulture" Ministry of Education and Science of the Republic of Kazakhstan (State Enterprise "Kaz. Research Institute of Horticulture and Viticulture" MES RK). - 12000 / 0824.1; appl. 24.07.2000; publ. 01.15.2001, Bull. ${ }^{1}$ 1.- 4 c.

6. Altayuly C. Extraction of phospholipids from crude vegetable oil and then receiving a phosphatide concentrate // Oils and fats. - 2010; 11(117): S. 20-22.

7. Altayuly C. Application of dried phospholipid concentrates of sunflower oil on the rotary thin film unit in the production of bakery // II AllRussia. Conf. with int. participation "Innovative technologies in the food industry.” - Samara, 2011; 38-39.

8. Magomedov G.O., Optimization of prescription components whipped unleavened // Hleboprodukty.- 2005; 12: 52-54.

9. Magomedov G.O, Production of non-yeasted pastry whipped // Hleboprodukty.- 2006; 6: 53-
54

10. Magomedov G.O., The influence of various factors on the rheological properties of whipped unleavened dough - 2007; 5C: 42-46.

11. Magomedov, G. O. Determination of optimum moisture whipped unleavened dough // Bakery. 2008; 9: 61-62.

12. Magomedov GO Rheological characteristics of whipped unleavened dough of whole grain wheat // Bakery. 2009; 1S. 48-49.;

13. E.I. Ponomarev. A method of producing whipped pastry; Appl. 17.07.06; Publ. 27.03.08, Bul. Number 9.

14. L.Y. Ryazanov. A method of producing corn bread unleavened Publ. 27.01.09, Bul. Number 3.

15. Green M., Applying quality assurance principles to food control // Food Control, 4 (1) (1993), pp. 2-6

16. Jongen W.M, Food supply chains and product quality: How to link sustainability and market / / Wageningen Pers, Wageningen 1999; 261-272

17. S. Leaper, a Practical Guide. Technical Manual No 38, s.1Campden \& Chorleywood Food Research Association (CCFRA), Chipping Campden 1997; 51.

18. Luning P.A. Food Quality Management: a Techno-managerial Approach, // Wageningen Pers, Wageningen 2002; 323.

19. M.J. Smit, Search for a common standard // International Food Hygiene, 1999; 10(4): 5

20. G.W. Ziggers, Agricultural entrepreneurship in a managerial perspective // $\mathrm{PhD}$ thesis Wageningen Agricultural University, Wageningen (1993) 156 p. (In Dutch). 